\title{
The Design, Analysis, and Manufacturing of Vibrating Table
}

\author{
Kadir Aztekin, \\ Defense University Turkish Military Academy, \\ Mechanical Engineering Department, Ankara, Turkey \\ E-mail: kaztekin@kho.edu.tr \\ Ergun Ates (Corresponding author) \\ Balikesir University, Faculty of Engineering, \\ Department of Mechanical Engineering, 10185, Balikesir, Turkey \\ E-mail: ergunates@gmail.com \\ Mehmet Tuncay Kaya, \\ Defense University Turkish Military Academy, \\ Mechanical Engineering Department, Ankara, Turkey \\ E-mail: mtkaya@kho.edu.tr \\ Dilay Koc \\ Balikesir University, Faculty of Engineering, \\ Department of Mechanical Engineering, 10185, Balikesir, Turkey \\ E-mail: dilay.koc@baun.edu.tr
}

\begin{abstract}
Composites are produced with different structures depending upon their components and production techniques. During the manufacturing of composite materials using the mold casting method, air bubbles formed in the inner structure need to be removed by vibration. Ultimately, the structure must be homogeneous and void-free. Within the scope of this study, composites produced using materials such as resins and aggregates were designed and analyzed, as well as a vibrating table that can be put to various uses. The vibrating table was manufactured following the successful design and analysis of results, and tested according to actual working conditions. It has been determined that the vibrating table can be easily used for its intended purpose when loaded under real working conditions.
\end{abstract}

Keywords: Vibrating table, Design, Analysis, Manufacturing.

DOI: $10.7176 / J S T R / 5-4-05$

\section{Introduction}

Composite materials are end products composed of at least two or more components and have superior characteristics compared to the components. One of the important problems in the production of composites is the inability to obtain a homogeneous structure. One of the most important reasons is the air voids remaining in the structure. The increase in the amount of air voids may cause one of the targeted features of the composite to be adversely affected compared to the ideal homogeneous structure. Vibration tables are manufactured and sold commercially. Vibration table is an important machine in the preparation of concrete molds used in the products considered to be produced by using aggregate and in constructions. Products in the market were examined and common characteristics were determined. The table sizes of the vibration tables with the smallest and largest dimensions are $400 \times 380 \times 450 \mathrm{~mm}$ and 1260x1270x1200 mm width, depth, and height, respectively. Another parameter is the electric motor power with which the table is driven. The smallest and largest values are $170 \mathrm{~W}$ and $746 \mathrm{~W}$, respectively. The electric motor is charged with mono phase $220 \mathrm{~V}$. In general, the number of revolutions is $3000 \mathrm{rpm}$ and below $[1,2,3,4,5]$.

In one study, design and manufacture of mechanical vibration table working at constant amplitude and different frequencies was performed. The table was driven by a variator and a sinusoidal motion was produced [6]. The fresh concrete should be compressed to the highest possible density in practice so that 
there are no air pockets in it. In this study, vibrations were applied to samples prepared for fresh concrete by a table vibrator for different durations. Vibrated samples had higher compressive strength and unit weight compared to non-vibrated samples [7]. All parameters affecting durability are also effective in the carbonation of concrete. Carbonation test can be done in normal environment and in laboratories by acceleration. In this study, concrete was compressed with the vibration technique and accelerated carbonation studies were carried out at different humidity rates on the samples which were presumed to have the least amount and the ideal amount of voids [8]. In the optimum design study of cement-based composite materials, cement, silica flour, crushed sand and crushed stone were mixed first and then water, hyper-plasticizer and steel wire were added to produce concrete. The obtained mixture was compressed with the mold it was poured into and taken to the vibration table [9]. The density and compressive strength of two different polyesters resins widely used in the market were studied. Different samples were produced with varying ratios of filler material and without filler material and then tested. Vibration was applied for 7 minutes at $3000 \mathrm{rpm}$ before gelling started in casting [10]. Although sample dimensions changed in the compressive strength measurement of concrete, the mixes prepared were taken from the same batch, placed on the same vibration table and compressed [11]. For engineering targets, a $1.5 \times 1$ meter large mechanical shaking table was designed and manufactured in order to be able to model the dynamic effect caused by earthquake effect in laboratory conditions. One-way movement of the shaking table was provided by the electric motor and speed, acceleration, frequency and period values were determined. With $30 \mathrm{~mm}$ horizontal movement, 0-190 rpm, the study conditions can range up to 600 $\mathrm{cm} / \mathrm{s} 2$ acceleration and $30 \mathrm{~cm} / \mathrm{s}$ speed [12]. Travertine residues and limestone aggregates from the Denizli basin and concrete sample mixtures in accordance with the pre-determined granulometry distribution curves were taken into molds and compressed in the vibration table [13]. The wooden plate produced in dimensions of $50 \times 50 \times 50 \mathrm{~cm}$ can provide one-way and harmonic motion ranging from $0-6 \mathrm{~Hz}$. From the cast on the plate, the displacements at the upper, middle and lower points were recorded with a camera and analyzed in the computer program [14]. By adding various wastes into the concrete mixture to reduce the cost of the concrete, both environmental protection and cost reduction were achieved. These samples were prepared using a vibration table and in accordance with the standards [15]. One of the important issues in the production of prestressed concrete and reinforced concrete components is to ensure that the fresh concrete is placed without gaps and has the desired strength characteristics. The mobility of fresh concrete is low. Therefore, in this study, vibration technique was applied in the compression of fresh concrete [16].

As it can be seen in the literature, vibration was applied to the aggregates molded for composite structures to be formed by addition of a material to different sized aggregates in particles, their density was increased by compression, and samples with high strength were obtained. The use of standards for the preparation and elimination of aggregates (TS EN 933-1 [17], TS706 EN $12620+$ A1 [18]) is very important. As can be seen in the studies, vibration tables with different driving forces and dimensions are designed and produced for different purposes. Based on our market analysis, commercial vibration tables are generally produced and sold for these applications. In this study, a table-type vibration device for workshop use, which can be used in general composite production, and work with non-large samples and interchangeable frequencies, was designed, analyzed and manufactured.

\section{Materials and Method}

\subsection{Design and Analysis}

In order to avoid voids in the mortar (matrix + reinforcement) material prepared in the casting of the composite samples and have a more homogeneous distribution, it is necessary to apply vibration and cease it before gelling starts. The technical characteristics of industrial vibration tables were examined, our working system was taken into consideration, and our original design was formed accordingly. In our design, the mass with changeable weight causing imbalance can be fixed at a different amount on a rotating disc. The electric motor can be rotated at a constant speed and also the revolutions can be applied at different values with the addition of a frequency converter to the system.

Solidworks program was used for the design process. The preliminary design is a table-type vibrator device that is equal to the external dimensions of the casting mold system and is given in Figure 1 with the expected general appearance details. 20 main elements were identified in the design (Figure 2). A total of 178 elements were obtained with two or more of some of the main elements and with the additional required components. In accordance with this design, the assembly was completed in Solidworks by taking the main element sequence numbers given in Figure 2 into account and with the required additional components. "Designed solid model vibration table" ready for casting after assembly is presented in Fig. 3.

36 | $P$ a g e 


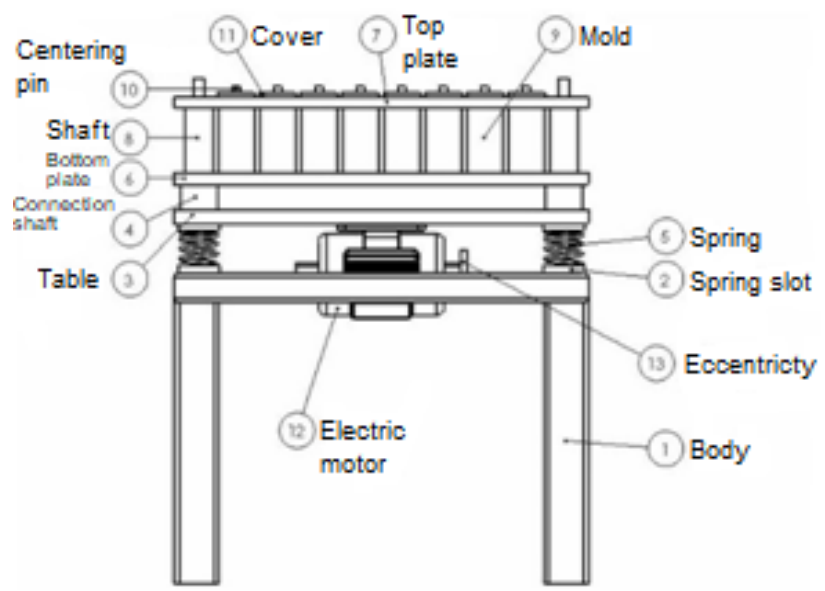

Figure 1. Design table-type vibrator.

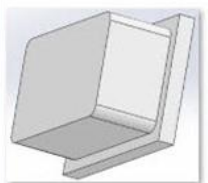

01 Plastic base

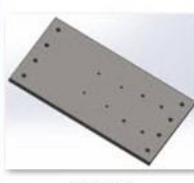

06 Table

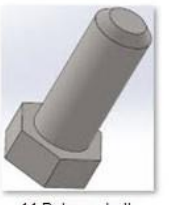

11 Balance bolt

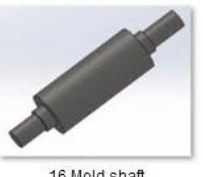

16 Mold shaft
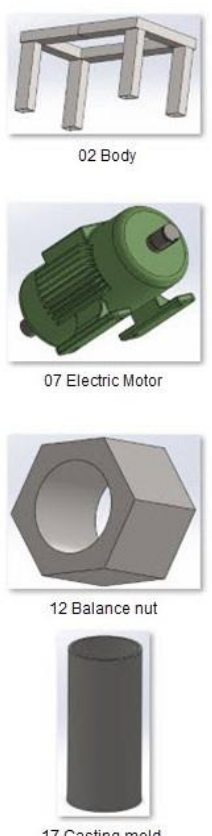
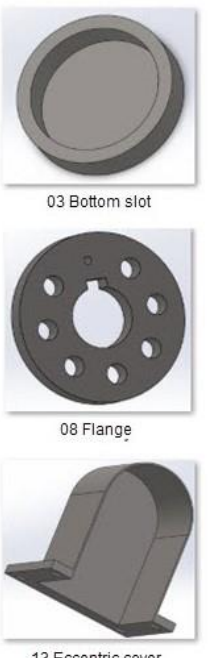

13 Eccentric cover

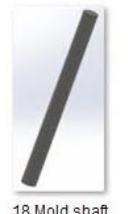

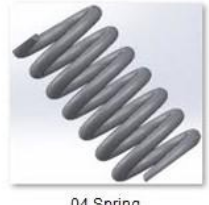

04 Spring

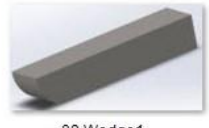

09 Wedge1

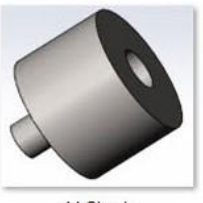

14 Chock

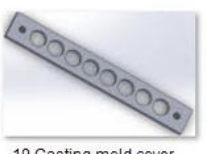

19 Casting mold cover

Figure 2. Drawing parts of the design in Solidworks.

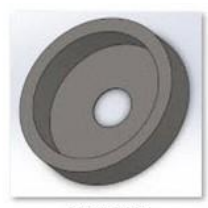

05 Top slot
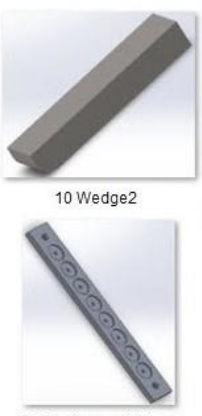

15 Casting mold base

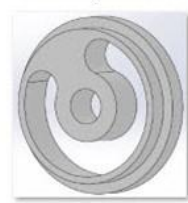

20 Cover

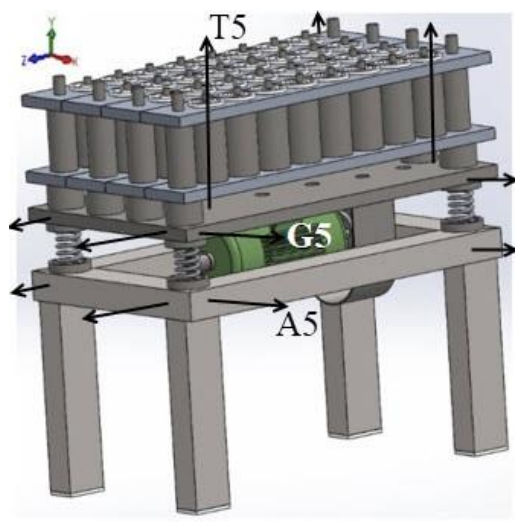

Figure 3. Assembly of the vibration table with Solidworks. 
The solid model with completed assembly in Solidworks (Figure 3) is ready for analysis with the simulation module in the program. A solid model was created for analysis. The system to be analyzed is the condition where the casting molds are full. This system was analyzed in the "non-linear dynamic analysis module". Analysis type was "solid mesh, mixed curvature based, Jacobean 4 points". During the mesh, maximum element size was taken as $103.9 \mathrm{~mm}$, and minimum element size was taken as $1.14805 \mathrm{~mm}$. According to mesh results "total number of knots was 177968 " and "total number of elements was 102150".

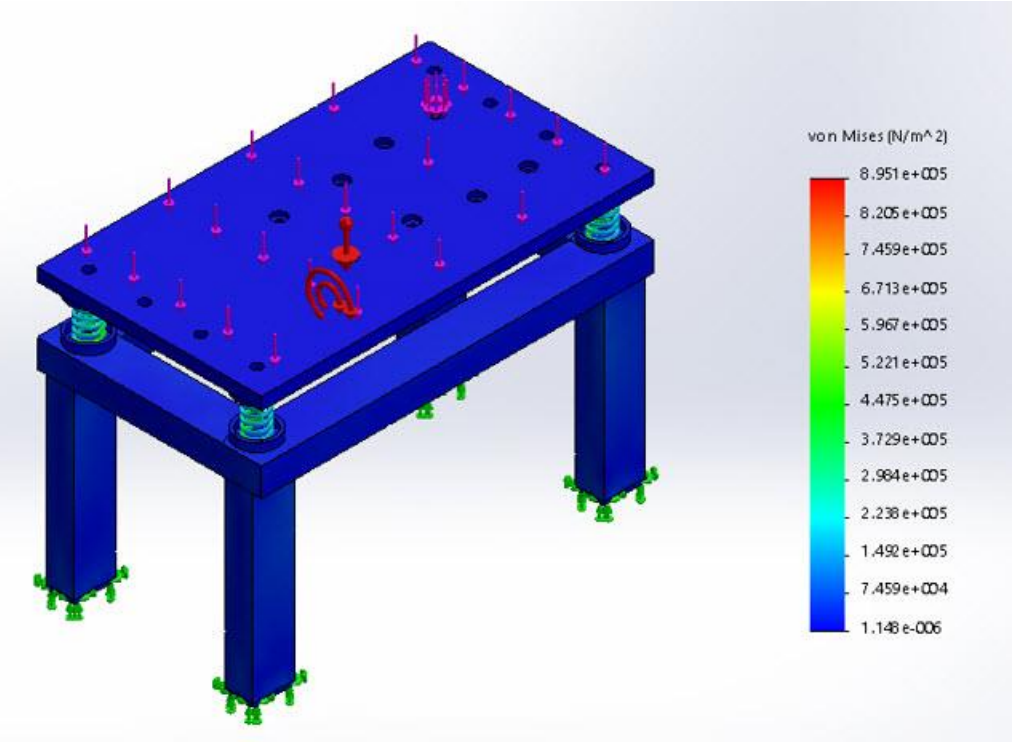

Figure 4. Stress analysis in SolidWorks.

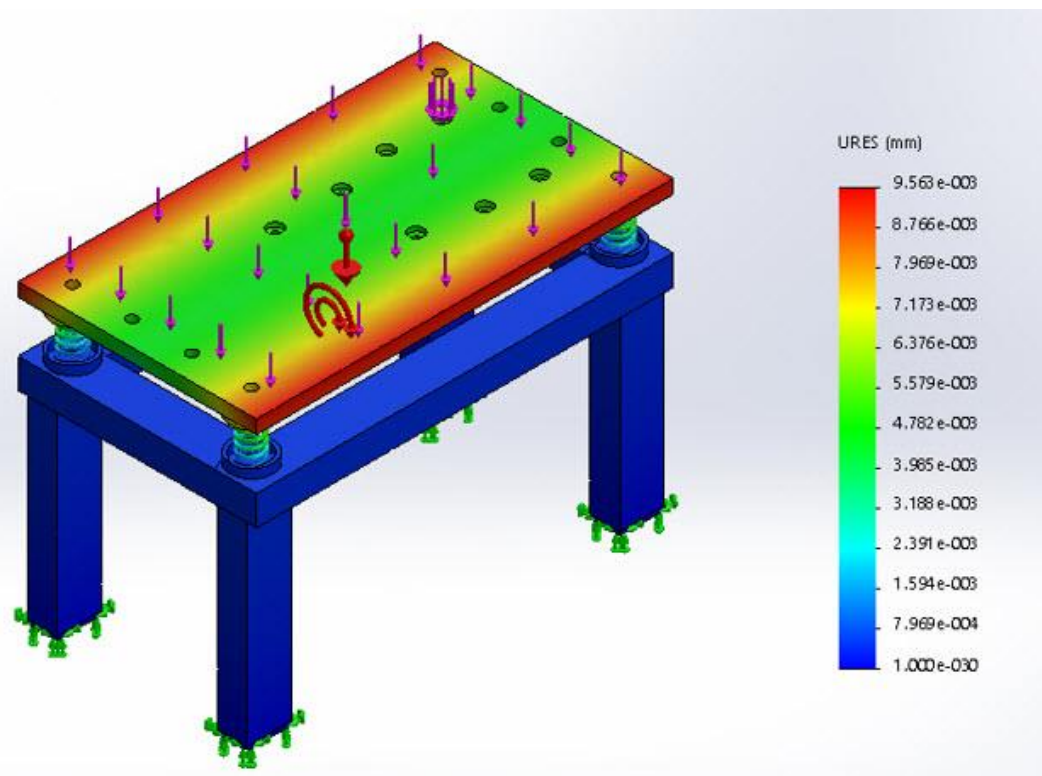

Figure 5. Displacement analysis in SolidWorks.

From the analysis, the highest load value was obtained as $0.895 \mathrm{~N} / \mathrm{mm} 2$ with production reaching the target and under load (401 N value). In this case, the smallest stress value was $1.148 \times 10-12 \mathrm{~N} / \mathrm{mm} 2$, which was small enough to be neglected (Figure 4). Under load, largest and smallest displacements were $9.563 \times 10-3 \mathrm{~mm}$ and $1.10 \times 10-3 \mathrm{~mm}$, respectively. Analysis results proved that, when load was applied, the vibration table assembled by combining different materials could successfully perform the vibration process with a high strength value.

\subsection{Manufacturing}

The design and analysis of the components were completed, and the components with finalized dimensions were manufactured. The frame and table part were produced from $60 \times 40 \mathrm{~mm}$ shaped material by using TIG welding. Overall dimensions of the table were $560 \times 320 \mathrm{~mm}$ and a height of $400 \mathrm{~mm} .15$ 
mm-thick mold bottom plate with dimensions of 580x340 mm was designed with eight vertical holes with a diameter of $16 \mathrm{~mm}$ that could be fixed when the plate was placed on the table and manufactured in a CNC milling cutter. In order to ensure the continuity of the vibration between the chassis and the table top, four compression springs with height of $67 \mathrm{~mm}$ and diameter of $47 \mathrm{~mm}$, modulus elasticity of $31.396 \mathrm{~N} / \mathrm{mm}$, and consisting of seven helices with a wire diameter of $5 \mathrm{~mm}$ [19] were fixed in the slots prepared on the table and table tray on all four sides. As a source of vibration, a mass was fixed to the shaft of a $1.5 \mathrm{~kW}, 2820 \mathrm{rev} / \mathrm{min}$ three-phase electric motor to cause an imbalance, and the motor was then fixed underneath the table. The vibration table was completed by assembling the manufactured elements (Figure 6).

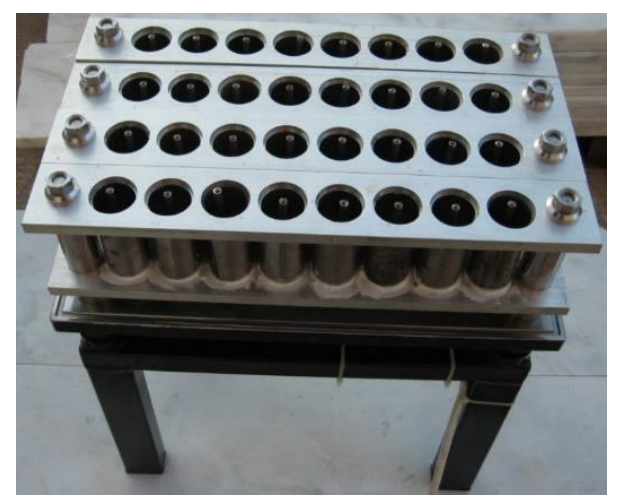

Figure 6. Vibration table ready for casting.

\section{Receiving instant data from the working system.}

In this study, data collected from certain points on the vibration table in accordance with TS2779 [20], TS7548 [21] and TS2782 [22] standards were evaluated. For the measurements to be made on each main bearing and near the bearing housing, measurements points were selected along the shaft axis and perpendicular to the shaft axis, and these points were selected as visible and accessible points on the machine. In terms of operating conditions, information such as temperature, humidity, rated voltage, current, frequency were specified at the moment of measurement. In terms of loading, loading condition was defined by evaluating the suitable and most difficult situation within the limits. In accordance with the standards, frequency was applied as $50 \mathrm{~Hz}$ at the limit of the driving motor. As is known, the vibration intensity is the root-mean-square (effective value) of the vibration velocity in the frequency range of 10 $1000 \mathrm{~Hz}$ and it is an understandable and characteristic value that determines the vibratory state of a machine. In this study, a vibration meter which could take measurements according to these standards was used as the main evaluation parameter.

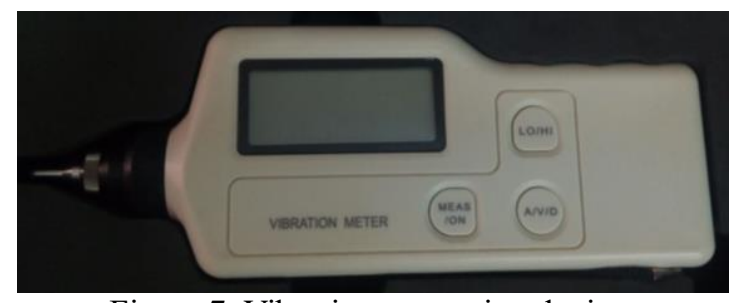

Figure 7. Vibration measuring device.

Using the vibration meter, data were collected as path, velocity and acceleration values from the manufactured vibration table under real load values during operation. The measurement device could measure path, velocity and acceleration values and had two different probes for complex and flat surfaces (Figure 7). 
Table 1. Comparison of data obtained from the vibration table and Solidworks analysis.

\begin{tabular}{|c|c|c|c|c|c|c|c|c|}
\hline \multicolumn{1}{|c|}{ Displacements of table vertical surfaces $(\mathrm{mm})$} \\
\hline $\mathbf{G}$ & 1 & 2 & 3 & 4 & 5 & 6 & 7 & 8 \\
\hline Device & $\mathbf{0 . 0 2 9}$ & $\mathbf{0 . 0 0 7}$ & $\mathbf{0 . 0 1 1}$ & $\mathbf{0 . 0 0 8}$ & $\mathbf{0 . 0 0 9}$ & $\mathbf{0 . 0 2 3}$ & $\mathbf{0 . 0 1 5}$ & $\mathbf{0 . 0 0 8}$ \\
\hline Analysis & $\mathbf{0 . 0 0 9}$ & $\mathbf{0 . 0 0 9}$ & $\mathbf{0 . 0 0 8}$ & $\mathbf{0 . 0 0 8}$ & $\mathbf{0 . 0 0 9}$ & $\mathbf{0 . 0 0 9}$ & $\mathbf{0 . 0 0 8}$ & $\mathbf{0 . 0 0 8}$ \\
\hline Difference & 0.02 & -0.002 & 0.003 & 0 & 0 & 0.014 & 0.007 & 0 \\
\hline \multicolumn{7}{|c|}{ Displacements of table surface $(\mathrm{mm})$} \\
\hline T & 1 & 2 & 3 & 4 & 5 & 6 & 7 & 8 \\
\hline Device & $\mathbf{0 . 0 5 5}$ & $\mathbf{0 . 0 3 2}$ & $\mathbf{0 . 0 3}$ & $\mathbf{0 . 0 1 1}$ & $\mathbf{0 . 0 3 3}$ & $\mathbf{0 . 0 3 2}$ & $\mathbf{0 . 0 5 1}$ & $\mathbf{0 . 0 4 7}$ \\
\hline Analysis & $\mathbf{0 . 0 0 8}$ & $\mathbf{0 . 0 0 8}$ & $\mathbf{0 . 0 0 8}$ & $\mathbf{0 . 0 0 4}$ & $\mathbf{0 . 0 0 8}$ & $\mathbf{0 . 0 0 8}$ & $\mathbf{0 . 0 0 8}$ & $\mathbf{0 . 0 0 4}$ \\
\hline Difference & 0.047 & 0.024 & 0.022 & 0.007 & 0.025 & 0.024 & 0.043 & 0.043 \\
\hline \multicolumn{8}{|c|}{ Displacements of table legs (mm) } \\
\hline A & 1 & 2 & 3 & 4 & 5 & 6 & 7 & 8 \\
\hline Device & $\mathbf{0 . 0 1 1}$ & $\mathbf{0 . 0 3 3}$ & $\mathbf{0 . 0 1 1}$ & $\mathbf{0 . 0 0 2}$ & $\mathbf{0 . 0 2 4}$ & $\mathbf{0 . 0 0 3}$ & $\mathbf{0 . 0 0 5}$ & $\mathbf{0 . 0 0 2}$ \\
\hline Analysis & $\mathbf{0 . 0 0 0 4}$ & $\mathbf{0 . 0 0 0 4}$ & $\mathbf{0 . 0 0 0 4}$ & $\mathbf{0 . 0 0 0 4}$ & $\mathbf{0 . 0 0 0 4}$ & $\mathbf{0 . 0 0 0 4}$ & $\mathbf{0 . 0 0 0 4}$ & $\mathbf{0 . 0 0 0 4}$ \\
\hline Difference & 0.0106 & 0.0326 & 0.0106 & 0.0016 & 0.0236 & 0.0026 & 0.0046 & 0.0016 \\
\hline
\end{tabular}

As the reference point of the table, the upper corner point of the table was selected so that the eccentric housing remained on the left side when viewed from the long edge of the vibration table. Measurement points were created in the coordinates determined as $(20 ; 20)$ in the $\mathrm{x}-\mathrm{z}$ (top) plane, $(-9 ; 20)$ in the $\mathrm{y}-\mathrm{Z}$ (height) plane, and $(20 ;-9)$ in the $x-y$ (width) plane according to the coordinate system shown in Figure 3 . The measurement processes were also performed on the other three corners of the tray going counterclockwise around the vibration table. For the top of the tray, these measurement points were defined as T1 to T8, respectively. For the side and width surfaces of the body, measurements points were defined around the corner points (similar to the determination of reference points for the tray) as G1 to G8. In the area under the springs, on the chassis where the pieces the springs were seated in were fixed, the distance from the coordinate system to the center of the chassis profile in the current position of the table and under load was taken as $20 \mathrm{~mm}$ in the $\mathrm{z}$ axis and defined as A1 to A8. Data obtained from the tray, body, and bearings are presented in Table 1. The points selected in the measurements are not detachable elements connected to each other but are single piece parts on the spring system. The aim here is to prevent any additional effect on the measurement results due to the coupling system. When the values presented in Table 1 were examined, it was seen that the maximum and minimum difference between the displacements on the "tray side surfaces" was $0.02 \mathrm{~mm}$ and $-0.002 \mathrm{~mm}$, respectively. The maximum and minimum difference between the displacements on the "top surface of the tray" was $0.047 \mathrm{~mm}$ and 0.007 $\mathrm{mm}$, respectively. When the difference between "displacements in the bearings" was examined, it was found that maximum difference was $0.0326 \mathrm{~mm}$ and minimum difference was $0.0016 \mathrm{~mm}$. When the device is taken as reference, the differences when compared with the analysis results are acceptable.

\section{Results}

Table was designed in the Solidworks program and analyzed by the simulation module; as the results were observed to be sufficient in terms of strength and function, the table was manufactured. Displacement was measured by a vibration meter from measurement points specified on the manufactured vibration table. Data obtained from the vibration meter were compared with the data obtained from Solidworks analysis, and it was found that the difference between the results was five percent or less. It can be concluded that the vibration table is suitable for the target job and therefore meets its design purpose.

In the analysis performed according to the force applied to the tray in the vibration table, the resulting stresses indicated that the table was extremely safe. The reason for the large weight of the tray was to ensure that the tray could perform its function despite the applied load, as a rigid structure without any displacement when it was placed on the springs in a horizontal plane. When the springs used in the vibration table are examined, it can be seen that the used springs can vibrate safely under current working conditions in case of a certain collapse under the load conditions, when not fully closed, due to the eccentric load. We can see this from the displacement results. The reason for the high modulus elasticity of the compression springs used in the vibration table is to ensure that they can withstand the large loads that will be applied on them. 
The profiles dimensioned in the design process were larger than the analysis results; this was due to the possibility of the vibration table being exposed to a larger load aside from the mold system used in the current study. In the case of transition from design to manufacturing, it can be seen that the method applied in this study can be used conveniently in similar activities demonstrating whether the product is reliable and suitable for the intended work.

\section{References}

1. UTEST, Material Testing Equipment. (2019), Vibrating Table. [Online] Available: http://www.utest.com.tr/en (March 07, 2019)

2. 3A, Laboratory Test Equipment, (2019), Vibrating Table. [Online] Available: http://www.3atestequipment.com/ (March 07,2019)

3. LIYYA, Laboratory Test Equipment, (2019), Vibrating Table. [Online] Available: http://www.liyatest.com/Home (March 07,2019)

4. TM, Testmak Material Testing Equipments, (2019), Vibrating Table. [Online] Available: http:// http://www.testmak.com/ (March 07,2019)

5. IDILLAB, Material Testing Equipment, (2019), Vibrating Table. [Online] Available: http://www.idillab.com/en (March 07,2019)

6. Karabulut A. (1998), Design of Fixed Amplitude and Different Frequency Working Mechanical Vibration Table. UCTEA Chamber of Mechanical Engineers, Turkey,39(464), 39-42.

7. Şimşek O., Bektaş S., Erdal M. (2002), The Effect of Vibration Time on Compressive Strength and Unit Weight of Concrete, Journal of Polytechnic, Gazi University, Turkey, 5(2), 185-193.

8. Gönen T., Yazıcıoğlu S. (2004), Development of Carbonation in Concrete in Different Humidity Environment, Science and Eng. Journal of Frrat Univ. Turkey, 16(2), 367-373.

9. Bayramov F., Taşdemir C., Taşdemir M. A., (2005). Optimum design of cement-based composite materials. Serie D: Engineering, İTÜ, Turkey, Vol. 4, Issue 3, 53-66, June.

10. Ateş E., Aztekin K., Çakır R., (2010). Determination of The Density and Compression Strength Optimization of Without Filling Material Composites, Journal of Engineering and Natural Sciences, YTÜ, Turkey, 28, 287-297.

11. Öztekin E., Eker Ç., Derin E., (2012). 150/300 mm or 100/200 mm Cylinder Specimen use for Concrete Compressive Strength Measurement. Ready Concrete, Ready Mixed Concrete Association-Turkey. P: 75-77, March-April.

12. Çelik S. B., Kumsar H., Aydan Ö., (2013). Motion Parameters of a Mechanical Shaking Table and an Application. Pamukkale Univ. J. of Eng. Sciences. V.19, Issue 5, P.224-230.

13. Çobanoğlu İ., Çelik S. B., Çam O., Etiz H., Kurşun M., (2014). Investigation of the Usability of Travertine Quarry Wastes As Concrete Aggregate, Pamukkale University, Journal of Engineering Sciences, V.20, I:3, P.92-99.

14. Özkaynak H., Özsoy A. E., (2016). Structural Dynamics Experiments Role in Civil Engineering Education: Small Scale Building Models Testing With The Vibrating Table, 3. Civil Engineering Education Symposium, TMMOB, UCTEA, Chamber of Civil Engineers, 8-9 January. 
15. Y1lmaz Y., (2014). Effect Of Using Flying Ash and Blast Furnace Slag in The Production of Concrete and Cost Analysis, Namı Kemal University, Institute of Natural and Applied Scinces, Turkey. MSc. Thesis.

16. Aktaş G., (2005). Computer-Aided Mould Design in The Production of Prestressed and Reinforced Precast Concrete Units, Çukurova University Institute of Natural and Applied Scinces, PhD. Thesis.

17. TS 706 EN 12620, (2013). Aggregates for concrete. Turkish Standard, TSE-Turkey, April.

18. TS EN 933-1:2012 EN, (2015). Tests for geometrical properties of aggregates - Part 1: Determination of particle size distribution - Sieving method. Turkish Standard, TSE-Turkey April.

19. Standart Yay. (2019). Compression Springs. [Online] Available: https://standartyay.com/en/

20. TS 2779, (1977). Mechanical Vibration of Rotating and Reciprocating Machinery Requirements for Instruments for Measuring Vibration Severity, Turkish Standard, TSE-Turkey April.

21. TS 7548, (1989). Mechanical Vibration of Large Rotating Machines with Speed Range from 10 to $200 \mathrm{r} / \mathrm{s}$ Measurement and Evaluation of Vibration Severity in Situ. Turkish Standard, TSETurkey, October.

22. TS 2782, (1977). Mechanical Vibration of Machines With Operating Speeds From 10 To 200 Rev/s - Basis for Specifying Evaluation Standards. Turkish Standard. TSE-Turkey, April. 